\title{
Homem ideal em revista no Jornal das Moças (anos 1950)
}

The ideal man in a female magazine: the Jornal das Moças (1950s)

\author{
Lucas Santos Rosa ${ }^{1}$ \\ Maria Cecilia Barreto Amorim Pilla ${ }^{2}$
}

\begin{abstract}
RESUMO
Cada período constrói estereótipos e seus próprios meios e regramentos que podem ser veiculados de diversas formas, os periódicos podem ser importantes maneiras de divulgar esses padrões, incutir ensinamentos, moldar categorias. Dessa forma é que o presente artigo pretende conhecer modelos que corresponderiam ao desejado "homem ideal", o tão almejado "bom para casar", que garantiria uma vida familiar segura e digna. Para tanto, constituem fontes dessa pesquisa a revista Jornal das Moças ao longo dos anos 1950, um periódico quinzenal que dirigido às mulheres das classes médias das cidades brasileiras aconselharam suas leitoras a buscarem idealizações de si mesmas e que em sua íntima procura e responsabilidade seriam capazes de encontrar seus pares que revelariam qualidades a elas complementares correspondentes ao companheiro "ideal".
\end{abstract}

PALAVRAS-CHAVE: "homem ideal"; "marido ideal", estereótipo do masculino.

\begin{abstract}
Each period builds stereotypes and its own means and regulations that can be conveyed in different ways, journals can be important ways to disseminate these standards, instill teachings, shape categories. In this way, the present article intends to know models that would correspond to the desired "ideal man", the longed for "good to marry", that would guarantee a safe and dignified family life. Therefore, the sources of this research is the "Jornal das Moças" during the 1950s, a biweekly magazine aimed at middle-class women in Brazilian cities that advised their readers to seek idealizations of themselves and that in their intimate search and responsibility they would be able to find their peers who would reveal complementary qualities corresponding to their "ideal" companion.
\end{abstract}

KEYWORDS: "ideal man", "ideal husband", male stereotype

\footnotetext{
${ }^{1}$ Licenciado em História - PUCPR e Mestre em Direitos Humanos e Políticas Públicas. Programa de Pós-graduação em Direitos Humanos e Políticas Públicas - PUCPR, Brasil. E-mail: lucas.s.rosa@hotmail.com

2 Mestre e Doutora em História pela Universidade Federal do Paraná. Professoa e Coordenadora do . Programa de Pós-graduação em Direitos Humanos e Políticas Públicas - PUCPR, Brasil. ceciliapilla@yahoo.com.br
} 


\section{Introdução}

O presente estudo faz parte de uma pesquisa maior em que se temdesenvolvido especialmente análises relativas à história e cultura da alimentação pautadas pela vida doméstica trazendo à tona elementos como gênero, moradia, educação no lar, enfim tudo o que envolve o espaço do lar e a papéis sociais relativos a este. Ligados a esse projeto estão professores, alunos de iniciação científica e também de mestrado. No andamento das pesquisas a temática ampliou-se e ganhou destaque a questão do trato das fontes, concretamente dos periódicos em geral.

Pesquisadores têm desenvolvido estudos tendo a imprensa periódica como base documental de seu "fazer histórico", especialmente desde a publicação da História da Imprensa no Brasil de Nelson Werneck Sodré, editada pela primeira vez em 1966, em que o autor analisou mais de um século de imprensa no Brasil (1808-1960). ${ }^{3}$ Depois dele, muitos outros estudiosos das Humanidades têm tomado a imprensa como fontes de análise. Em especial historiadores como Martins (2008, p. 17) que nos trazem um importante alerta, o "documento revista" diz ela, oferece uma gama de opções de análise, texto, imagem, técnica, ilustração, papel, formato, que podem ser consideradas no todo ou em partes, no entanto é preciso não se deixar envolver pelo caráter lúdico dos periódicos, tê-los como verdades absolutas, sem crítica externa.

No mesmo sentido também Pinski (2014, p. 46-47) avisa que cada periódico tem seu público alvo e espera agradá-lo. Assim é que em Pilla (2016, p. 383) o alcance da imprensa sobre a sociedade se estabelece em uma relação de troca, em que uma influencia a outra. Assim, ela era o objeto e ao mesmo tempo o sujeito de sua própria capacidade influenciadora. "[...] a um só tempo, objeto e sujeito da história brasileira”. (MARTINS; LUCA, 2008, p.

\footnotetext{
3 A primeira edição de História da Imprensa no Brasil foi publicada pela editora Civilização Brasileira, depois saíram outras quatro edições, uma da Graal de 1977, uma da Martins Fontes de 1983, uma da MaudX e 1999 e finalmente a da Intercom/EDIPUCRS em 2011.
} 
8). Ao lado do rádio - era o mais amplo meio de comunicação com a população civil, assim como o de maior propagação no período estudado. "Nesse ponto da história da mídia é possível comparar a imprensa e o rádio como mídias que influenciavam o fornecimento de informações e a formação da opinião pública”. (BRIGGS; BURKE, 2016, p. 248).

A imprensa escrita conseguiu coexistir com os novos meios de comunicação, como o rádio e a televisão, e apesar de perder parte de sua influência ao longo do tempo, na década de 1950, ela permanecia como uma grande disseminadora de ideais, normas e as novidades de bens de consumo, em especial voltados ao público feminino:

A imprensa moderniza-se, principalmente no que diz respeito às revistas ilustradas. $\mathrm{O}$ vínculo entre imprensa feminina e consumo se intensifica acompanhando o crescimento da indústria de bens ligados à mulher e à casa e o aumento do poder aquisitivo de setores da população. (PINSKY, 2014, p. 19).

A ampliação do consumo era resultado da industrialização, fazendo com que edições de revistas e de jornais fossem produzidas em maiores quantidades e consequentemente alcançando um público maior do que em períodos anteriores. Como prevê Valdívia (2008, p. 24), "diante do American way of life (modo americano de vida), muito bem expresso nos meios de comunicação foi apresentado à sociedade brasileira a necessidade do bemestar, expresso no consumismo de bens materiais".

A influência dos periódicos também é vista quando se fala da publicidade, uma vez que, com o final da Segunda Guerra Mundial (19391945) um novo ideal de modo de vida e de consumo vai espaço e o seu principal meio de comunicação é cada vez mais o periódico. Para Lobato (2013, p. 4), "a introdução de um modelo de vida baseado no consumo e o aumento dos índices de escolaridade deram um impulso ao mercado editorial".

Diante de uma imprensa poderosa que veicula publicidade e propaganda que trazem um novo olhar sobre a modernização e os novos mercados, em especial nos anos do governo de Juscelino Kubistchek: 
Os anos JK abriram novos horizontes para a publicidade. Ocorreram mudanças significativas na estrutura produtiva do país. A intensificação do processo de substituição das importações determinou a maior diversificação da atividade produtiva, em especial a indústria, e surgiu a necessidade do suprimento de bens intermediários e de bens de capital. O desenvolvimento acelerado da industrialização permitiu o crescimento das áreas urbanas e alterou o mercado consumidor brasileiro. De acordo com Roberto Simões, existiam no país 500 agências de publicidade que empregavam 5 mil pessoas. O setor que mais investiu em propaganda foi a indústria automobilística (General Motors, Ford, DKW-Vemag, Mercedes-Benz). O jornal ainda era a mídia principal, com $28 \%$ de investimento publicitário. A seguir vinham o rádio com $16 \%$, as revistas com $12 \%$ e a televisão, com $6 \%$. (ABREU; PAULA, 2007, p. 14).

A partir dessa premissa o presente artigo quer abordar a questão do modelo desejado de masculinidade veiculado em um periódico destinado ao público feminino, o Jornal das Moças, ao longo dos anos 1950. É importante observar que uma revista cujo público é essencialmente feminino acaba trazendo em suas páginas uma série de notícias, artigos, anedotas, contos, colunas e mesmo publicidade que ao dirigir-se às mulheres, veiculam e projetam desejos sobre estereótipos do masculino. Afinal, muito da imprensa feminina da época trouxe conselhos em como seduzir, conquistar, e arrebatar o coração de um "marido perfeito". Dessa forma é que os arquétipos aqui analisados não estão enquadrados na questão feminina, mas sim no masculino.

\section{O Jornal das Moças e o "homem ideal"}

O Jornal das Moças foi um periódico semanal produzido na cidade do Rio de Janeiro entre 1914 e 1965, e que teve circulação nacional. Saía toda quarta-feira e podia ser comprado nas bancas ou por assinatura. Foi fundado por Agostinho de Menezes, era propriedade da Editora Jornal das Moças Ltda. Possuía por volta de 70 páginas e versava sobre assuntos de interesse do público feminino de sua época. Tinha notícias sobre música, cinema brasileiro e internacional, coluna de anedotas, a "Troças e Traços", o 
conto da semana e notícias do rádio, trazia também novidades sobre o universo da moda, culinária e os últimos lançamentos de cosméticos, eletrodomésticos, e outros produtos para o lar e para a família.

A escolha da revista se deu principalmente por seu caráter nacional e também por sido veiculada durante tanto tempo, cerca de 50 anos, sem ter tido grandes modificações no que diz respeito ao público a que se destinava e às posições em relação à sociedade e à formação das famílias que pretendia influenciar. De acordo com seus editores o Jornal das Moças é o melhor do mercado, ou que ele preserva a moralidade e os bons costumes, assim como tem caráter familiar. "O Jornal das Moças é a revista da família". (JORNAL DAS MOÇAS, 1953, n. 1960, p. 21).

Essa intenção é expressa na edição de aniversário de 1956, em que os editores querem agradecer o carinho e assiduidade de suas leitoras, aproveitam para enaltecer as tendências criadas pelo próprio jornal e reafirmam a intenção de preservar a família e preparar a mulher para agradar seus futuros maridos:

O JORNAL DAS MOÇAS tem levado a todos os lares ensinamentos agradáveis e úteis formando inúmeras boas donas de casa. Quer nos figurinos, quer nos bordados, tricôs e outras idéias interessantes que fazem da mulher aquelas que os homens desejam para um lar, concorre o JORNAL DAS MOÇAS para o engrandecimento da família. E uma família unida, forte e digna, forma, também, uma grande pátria, que, por seu turno, tem que ser admirada e respeitada no concerto das nações civilizadas. Êste tem sido o papel preponderante de JORNAL DAS MOÇAS no transcurso de sua existência. Esta, a nosso ver, é a importância da imprensa. (JORNAL DAS MOÇAS, 1956, n. 2146, p. 11).

Influenciando então para a criação de uma nação forte e bem orientada pela moralidade, avançando em questões de cunho internacional, preparada para ocupar diante das demais nações civilizadas o lugar que merece por ter modelos de família propagados pela revista. Se estabelecia a revista como uma espécie de guia para as jovens leitoras para a vida em 
sociedade. Assim é que se exercia uma tentativa de institucionalizar e normatizar hábitos para as novas gerações, podendo-se ver uma representação da repetição constante do modelo desejado de homens e mulheres, contribuindo para a permanência de estereótipos que correspondem especialmente de um homem másculo, futuro chefe de família.

Dentre as formas de difusão desses ideais, o Jornal das Moças, assim como outras revistas femininas do período, procuraram, por meio de contos, reportagens, entrevistas, sugestionar as suas leitoras, reforçando características de gênero, motivando o combate de influências que considerassem nocivas ao modelo "tradicional" de família. Diante de um quadro de transformações vividos pelos anos 1950, a revista faz esforços para sem perder o controle sobre o que pretendia preservar dos papéis do feminino e do masculino, condicionar seu público, renovando-se em campos que não afetassem as atribuições sociais.

Sendo assim confirma a importância da família e para tanto defende a criação de filhos condizente à distinção de gêneros e funções "naturais", auxiliando mulheres e homens em bem desempenharem suas atribuições esperadas. Pois como diz Baubérot (2013, p. 192), é dentro da família, de forma ao mesmo tempo precoce e inconsciente que se operam as primeiras diferenciações e que, antes mesmo de tomar consciência de sua condição de ser sexuado, a criança começa a interiorizar as normas que se referem a seu gênero. Tais normas aparecem especialmente vinculadas às figuras paternar e maternas, ou ainda, dos avós, tios e irmãos.

Ao homem-marido cabe a preservação moral da família, e a isso correspondem atitudes como trazer o sustento para o lar e manter a família dentro dos limites da moralidade. "A glória do homem está na retidão e no bom emprego de sua vontade e a glória da inteligência é servir para fazer triunfar a moral”. (JORNAL DAS MOÇAS, 1953, n. 2021, p. 23).

Frente aos novos tempos o periódico procurou tomar posicionamento, e num pequeno artigo denominado "A Censura" defendeu:

Pertencemos a uma revista que durante todos esses anos de sua longa existência vem mantendo uma linha de conduta que jamais se afastou dos 
bons princípios morais. Estamos, por isso mesmo, ao lado dos que trabalham pela moralização dos costumes mesmo que isso possa trazer prejuízos a terceiros. [...] Não defendemos, jamais, a imoralidade, mas não queremos ver, também, a musica popular revestida de sete saias, numa época em que decotes alcançam grandes 'latitudes'. (JORNAL DAS MOÇAS, 1957, n. 2197, p. 44).

Dessa forma reforçou intenções moralizadoras enfatizando que perante situações de conflito jamais se posicionaria a favor de algo que a equipe editorial considerasse uma afronta à sociedade pré-estabelecida. Desta forma, segundo Pinski (2014, p. 35), o Jornal da Moças mostra sua parcialidade frente à rebeldia da juventude norte-americana veiculada principalmente por meio do cinema, criticando ícones como Elvis Presley em uma matéria de 1957, criticando abertamente os pais que permitiam o contato de seus filhos com esse estilo de múscia por não verem nada de errado num ritmo musical obsceno, denunciando o risco da juventude tornar-se fraca de caráter.

[...] os responsáveis sóbrios que nada viram de máu nos 'cem por cento' esqueceram-se que êles seriam os culpados, um dia, da falta de decôro de seus queridinhos [...]. Os papais não têm forças para evitar que seus filhos iniciem a vida com o nome nos jornais e os chefes não conseguem fazer com que filmes comuns possam ser vistos em ambiente normal. [...] O que há é isso: FRAQUEZA. [...] Encham a cidade de Rock, mesmo nos clubes, e em pouco tempo a coisa passa e volta à normalidade. Depois... os papais que pensem nos filhos que estão dando ao mundo de amanhã. (JORNAL DAS MOÇAS, 1957, n. 2172, p. 5).

Culpando a irresponsabilidade dos pais, o periódico se coloca contra o novo movimento musical e contra as famílias permissivas. A matéria foi publicada no momento em que ocorria a estreia do filme Love Me Tender, que repudia e torce para que não passe de um movimento passageiro. Seria o requebrado de Elvis uma ameaça ao estereótipo do machão, arrimo de 
família? No entanto, em 1958, parece mudar de ideia, e em uma nota de rodapé a revista se retrata.

Muito se falou a respeito de Elvis Presley. Falou-se mal do rapaz só porque êle divulgava um novo gênero de música e porque se mexia um pouco mais que o comum, quando entoava as suas canções e os seus 'rocks'. Mas o rapaz até que é uma boa pessoa e um artista razoável no gênero. (JORNAL DAS MOÇAS, 1958, n. 2245, p. 3).

Algo comum nos artigos que compõem a revista é que em sua maioria não têm autoria, por conta do corpo editorial da revista ser composto apenas por homens, ao menos os maiores cargos, nem sempre é possível determinar o sexo de quem escreve. Segundo Pinski (2014, p. 28), essa ausência é uma dificuldade para identificar quem escreveu o quê. O periódico também aceitava colaboração externa para determinadas sessões, como as charges, o que dificulta ainda mais a possibilidade de saber quem escrevia cada artigo ou coluna, uma vez que a publicação poderia ser feita, para guardar sigilo, por meio de pseudônimos. "Os leitores que desejarem enviar colaborações deverão remetê-las sob assinatura, embora desejando que sejam publicadas com pseudônimos. As 'piadas' ilustradas deverão ser desenhadas a tinta nankin". (JORNAL DAS MOÇAS, 1959, n. 2296, p. 11).

Uma das poucas exceções de artigos com autoria era a coluna "Carnet das Jovens" redigida originalmente por Dorothy Dix - uma jornalista estadunidense - que tinha seus artigos traduzidos por funcionários do Jornal das Moças. Essa coluna tinha o intuito de responder a perguntas enviadas para a colunista que aconselhava as leitoras em como agir diante de determinada situação. $\mathrm{Na}$ verdade, as dúvidas eram de moças norteamericanas, e seus questionamentos eram da década de 1940, pois Dorothy havia falecido em 1951. Ou seja, utilizavam conselhos dados pela jornalista na década anterior. Isso seria uma pista de resistência da revista em reconhecer que o tempo passou e que talvez as dúvidas já não fossem mais as mesmas? 
Dorothy Dix em suas colunas dá muitos conselhos e em especial alguns do mundo masculino. Quando questionada sobre os efeitos da ausência do homem no lar sobre os filhos, a colunista logo sai em defesa do homem que por conta de seu trabalho se ausenta de seu lar, dizendo que isso em nada afeta seus reais sentimentos em relação a seus filhos ou à sua esposa, o importante é que o homem seja trabalhador.

Quanto mais assíduo seja seu espôso a seu trabalho, maior bem estar terão ela e seus filhos. Deve ela pensar também que seu marido tem suficiente capacidade para saber quando pode ou não ficar em casa, pois os pais têm também amor a seus filhos, sentindo prazer em estar com êles. [...] direi que as espôsas que fazem estas queixas, seguramente nunca fazem objeção quando o marido lhes traz um bom cheque, para que elas possam gastar a vontade. (JORNAL DAS MOÇAS, 1950, n. 1816, p. 57).

O marido provedor não falha e sua companheira não deve reclamar daquele que corresponde às qualidades que a sociedade deseja dele. $\mathrm{O}$ homem tem a necessidade de prover a sua família e lhe dar uma boa qualidade de vida e, caso esteja ocupado demais para dar atenção a eles, a ausência se justifica uma vez que ele está cumprindo o seu dever de pai e esposo e exercendo a influência direta em seus filhos de como um indivíduo másculo deve ser: trabalhador e esforçado, sem a necessidade de demonstrar seus sentimentos afetivos por sua família o tempo inteiro, já que assegurando seu bem-estar já está indiretamente mostrando ser zeloso e amoroso.

A ausência masculina não é culpa do homem, ela decorre do suas funções "naturais". Assim como a traição que é vista quase como um instinto natural, por isso se recrimina o ciúme. É do masculino trair, assim como é do feminino o perdão.

Dorothy além de culpabilizar a esposa pelo ciúme e pela incompreensão, também a culpa pelo desleixo de um lar desarrumado. Se o marido passa horas jogando e tomando café com os amigos talvez seja porque a mulher não esteja cumprindo com seus papéis o que impede que o 
marido cumpra o seu. Assim a mulher desleixada, assim como a ciumenta, peca duas vezes, peca por ela e por provocar desvios morais na conduta do marido. Em um artigo denominado "Esposas Preguiçosas" Dorothy aponta,

Sei de muitas mulheres que se queixam assim: - 'Meu marido sai tôdas as noites com os amigos ao café. Joga. E às vezes chega à casa com odor a bebidas'. De quem é a culpa? - Perguntaria a muitas dessas senhoras. - A culpa é sua, minhas senhoras. A pouca atenção que as senhoras prestam a seus esposos os afastam do lar. Com razão saem a rua à procura do que não encontram em casa. A boa dona de casa, jovem ou idosa, recém-casada ou com vinte anos de matrimônio, deve procurar atender às necessidades de seu lar, ao gôsto de seu esposo, para que não tenha êste protexto de passar no café ou frente a uma mesa de jogo [...]. (JORNAL DAS MOÇAS, 1953, n. 1959 , p. 15).

Mas há também em uma coluna uma carta de um homem que pede conselhos a Dorothy, alegando que em breve irá se tornar pai que quer saber como educar corretamente o filho. Nessa ocasião a autora não perde tempo em insistir na necessidade de um lar harmonioso, reafirmando a ideia de "família perfeita". Ao homem cabe evitar as discussões, ser mais tolerante e refrear seus instintos masculinos que tendem a ser agressivos.

Cada filho representa um problema diferente e isolado, de acôrdo com o caráter familiar, com o ambiente e com os meios de vida dos pais. Sem embargo, há um denominador comum, a tarefa requer a cooperação de pai e mãe. [...] Mas, antes de tudo, uma boa parte da harmonia conjugal deve ser proporcionada pelos próprios esposos. É preciso evitar as discussões, o disse me disse, e proceder sempre com tolerância para os pequenos defeitos ou caprichos dos demais, pois cada um de nós é passível de errar. (JORNAL DAS MOÇAS, 1950, n. 1836, p. 44).

Devem também os pais serem exemplos para seus filhos, diz a coluna "Os filhos são uma simples cópia de seus pais”, 
Um pai, por exemplo, diz a seu filho que não deve beber álcool, que é um vício terrível e que lhe faz mal, e, todavia, desde que essa criança nasceu tem visto seu pai chegar muitas vezes em casa completamente embriagado. Como quer que seu filho, mais tarde, rechace êste vício? [...] As censuras nada adiantam, os exemplos valem mais que todas as prédicas, por mais bem faladas que sejam. (JORNAL DAS MOÇAS, 1951, n. 1876, p. 54).

Quando a revista orienta as jovens a procurarem e se acaso acharem não perderem o dito "marido perfeito", acabam novamente reforçando papéis sociais pré-estabelecidos.

Portanto, hoje, como em todos os tempos, nossa regra primordial consiste em nos dedicarmos ao bem-estar da família, enquanto nossos maridos se empenham em mantê-la. O 'marido perfeito' está ao nosso alcance, se cuidarmos de seu bom-humor e não considerarmos nunca como obrigação ou uma coisa natural - sua eventual colaboração nos trabalhos domésticos. O trabalho caseiro é nosso; o marido tem o seu... (JORNAL DAS MOÇAS, 1959 , n. 2285, p. 26).

Estabelecendo modelos aos maridos o jornal acaba por alertar as mulheres pontos que poderiam demonstrar que elas haviam escolhido o homem errado para casar. Certamente este seria aquele que não quer trabalhar, que não é honesto e que portanto é incapaz de por meio de suas atividades profissionais e fidelidade à esposa manter sua família protegida e feliz. É um companheiro que fere a rotina familiar com bebedeiras, jogos e outras vergonhas.

O homem deve ser forte e para isso a esposa deve agir para que ele também se sinta forte. Isso é o que o artigo "A Felicidade se Edifica a Cada Dia", parece dizer quando orienta, "Deixem-no crer sempre que vocês têm necessidade dêle e isto aumentará sua confiança em si mesmo. Não lhes faça concorrência no seu próprio terreno”. (JORNAL DAS MOÇAS, 1950, n. 1826, p. 9). 
O homem másculo é bonito? Esse é o tema do artigo Hollywood diz adeus aos rapazes bonitos, trazendo o ideal proposto pela indústria cinematográfica do momento.

Conferindo a lista de 1950 dos atores mais em evidência, você verifica que não há um tipo de 'rapaz bonito' entre os mesmos. A presente produção de galãs em evidência aparentemente substituiu o tipo bonito pelo tipo másculo. E pensa você que a audiência feminina está se queixando desta mudança? Absolutamente, não. Elas adoram o tipo atual de galã. [...] Para maiores provas de que a era dos rapazes bonitos terminou, reparem nas novas atrações de bilheteria do presente, com 'astros' como David Brian, Marlon Brando, Macdonald Carey e Edmund O’Brien... Sim, é bem explícito que as fábricas de Hollywood não estão mais à procura de Rudolphs Valentinos ou John Gilberts. (JORNAL DAS MOÇAS, 1951, n. 1864, p. 4647).

Parece que a masculinidade desse período não se mede pela beleza. $\mathrm{O}$ belo e delicado parece se relacionar ao feminino. A rusticidade e os traços duros que demonstram força física e a seriedade são os traços ideais do macho galã. $\mathrm{O}$ astro do cinema mudo feminino e andrógeno definitivamente estava fora de moda. Eram tempos de Clark Gable, "um dos mais completos artistas da tela, um tipo viril, que em todos os seus papéis desempenha o tipo do homem verdadeiramente homem, agradando, por isso, a tôdas as gerações". (JORNAL DAS MOÇAS, 1957, n. 2215, p. 2). Seu oposto eram os atores indesejados, o contra modelo do esperado,

Acontece que para não perder o hábito, também os homens passam pelos seus períodos de transformação. E então vemos os rapazes que dançam como mulher, os bonitões com penachos no antigo estilo 'pega-rapaz' do penteado feminino, ou os meninões de camisa vermelha com laço na cintura e até cria várias classes sociais como a dos jovens da 'juventude transviada'. Com George Nader não há nada disso. Êle é um tipão de homem como devem ser os homens, não obstante o seu grande topete. (JORNAL DAS MOÇAS, 1958, n. 2229 , p. 2). 
A influência estrangeira, mais uma vez, aparece presente nas páginas da revista e no dia a dia da família brasileira da década de 1950. Essa presença da indústria hollywoodiana está num artigo denominado "Os 'astros' dão conselhos aos noivos" (JORNAL DAS MOÇAS, 1951, n. 1867, p. 4-5), em que diversas estrelas da época, entre elas Bing Crosby, William Holden, Bob Hope e Alan Ladd aconselham os noivos como tratarem suas futuras esposas e futuramente seus filhos, indicando-lhes como manterem sua família dentro de um futuro idealizado e o mais próximo possível da suposta perfeição.

Mas a imagem do homem de verdade é reforçada também em anúncios, e não há nada de perigoso à masculinidade preocupar-se com os cabelos, pelo menos é o que a publicidade contra a calvície defende.

As atenções para com os cabelos não dependem do sexo. O homem também deve cuidar de sua cabeleira. Se a êle fôsse negado êsse direito, então porque tão grande é o mêdo de uma possível queda dos cabelos? De uma calvície precoce. [...] O uso das brilhantinas deve ser controlado; Todo o excesso de gordura é prejudicial. [...] O homem deve saber cuidar da saúde de sua cabeleira. (JORNAL DAS MOÇAS, 1958, n. 2255, p. 5).

Já quanto ao figurino, não são muito bem vistos, "os homens que se importam muito com o último figurino da moda masculina não fazem, em geral, muito boa figurinha no mundo intelectual". (JORNAL DAS MOÇAS, 1950, n. 1823, p. 32). O homem másculo não se importa tanto com a moda, e o que se importa é malvisto por não se encaixar no padrão de um homem másculo e intelectual, pois perde tempo - na visão da masculinidade - com questões pouco importantes e ligadas à feminilidade. Indiretamente, se vê mais uma vez a fragilidade da masculinidade e o medo da aproximação de questões femininas. Assim como os que se preocupam demais com a estética e os cuidados do corpo ou do rosto, inclusive no cinema, "um bom ator não precisa de make-up, diz Charles Laugthon" (JORNAL DAS MOÇAS, 1950, n. 1803, p. 5).

\section{Considerações finais}


Gênero elevado a uma categoria social e analisado sob esse ponto de vista possibilitou o entendimento de que o masculino e/ou a masculinidade é algo construído, tal como o é o feminino e ou a feminilidade. O estereótipo do masculino se edifica e se perpetua por meio da binaridade em contrapartida ao feminino. A ligação entre os opostos em uma sociedade tradicional permite compreender idealizações do maco como o forte, agressivo, dominador e rústico complementado pelo feminino delicado, compassivo, submisso e belo.

O Jornal das Moças na década de 1950 veiculou modelos a serem desejados por suas leitoras como "maridos-pais ideais", que deveriam corresponder em igual medida aos modelos esperados de "esposas-mães ideais". Em uma espécie de história a contrapelo se procurou ler nas entrelinhas em textos destinados às mulheres o que buscar em companheiros idealizados. Os artigos, colunas, anúncios, ao veicularem tantas obrigações a serem seguidas pelas mulheres também em grande medida prometeram a elas que seus esforços seriam recompensados por um bom casamento. Oras, um bom matrimônio só se realiza plenamente entre casais plenos, preparados para a procriação, para enfrentar as mais diversas dificuldades, o homem sendo o forte provedor e a mulher a sublime educadora, paciente, terna e fiel.

Um artigo do Jornal das Moças de janeiro de 1959 (edição 2276, p. 55 ), revela o resultado de uma enquete realizada em um clube feminino de Londres sobre como seria o marido ideal, ele seria, "culto como um francês; atlético como um grego antigo; bondoso como um australiano; diplomata como um suíço; humano como um inglês; rico como um norte-americano...".

Imaginando que todo homem é um "marido em formação", como encontra-lo? Que critérios fazem de um rapaz alguém atraente para o altar? Como reconhecê-los? Em sendo homem, como posso eu me fazer reconhecer por mulheres que me complementem? Lembrando-se que a ideia de complementaridade entre os sexos parece ter sido ainda a baliza social da sociedade brasileira dos anos 1950, para todo masculino há um feminino que o completa, e essa complementaridade deve revelar equilíbrio. 
Apesar de muitas serem as orientações no sentido da construção da "mulher-esposa-mãe ideal" que deveria procurar alguém que lhe fosse à altura para o casamento, em algumas edições isso foi apontado como impossível. Na coluna "Troças e Traços" de 13 de dezembro de 1951 (edição 1904, p. 4) em uma anedota "mulheres" duas pessoas falam:

Uma - Então, a Zizinha ainda anda à procura do homem ideal para casarse?

Outra - Não; abandonou isso. Agora, anda simplesmente à procura de um marido.

Em edição de 31 de outubro de 1957 (edição 2211, p. 13), em artigo encaminhado "às noivas e esposas", em que se trata do quanto os "homens não gostam de mulheres ciumentas", em meio a conselhos sobre controlar o ciúme, há um pequeno trecho em que a possível (o artigo não tem autor) escritora logo alerta, "a mulher ideal não existe, e nem também o homem ideal", no entanto, na continuidade da escrita "a autora" esclarece seu ponto de vista dizendo que o homem ideal é "moldado pela mulher". Talvez corresponda ao mesmo protótipo em que na edição de 1959, no artigo "Feminismo a Varejo" (edição 2287, p. 20-21), em que "o autor" afirma que o "marido ideal está a nossa alcance". Parecendo partir do pressuposto que "a mulher faz o homem", e este para ser ideal deve ser antes de tudo confiante, aconselha em fazer-lhe enaltecimentos, "pois todo homem gosta de ouvir elogios, saber que apreciam seu talento, sua capacidade profissional, seu senso de negócio, etc.". De tudo isso o que nos parece é que o "homem ideal" é sim uma construção desse masculino trabalhador, competente, confiante, forte, mas que só existe se reconhecido pela sua complementar "mulher ideal".

Já a edição de 24 de julho de 1958 (edição 2249, p. 22-23), em "Curiosidades Femininas" traz um enquete sobre o que seria o "homem ideal" para as suecas, $73 \%$ declararam que o homem ideal deve trabalhar e gostar de seu trabalho; apenas $6 \%$ disseram que deve ser bonito; e $21 \%$ disseram não se importar com a calvície ou obesidade. As mais jovens se preocuparam menos com a segurança financeira do que as mais velhas. No geral o que se pode observar é que o destaque vai para o trabalho e a 
fidelidade, já que esta apareceu como qualidade importante para 79\% das entrevistadas.

De todo o exposto considera-se que o Jornal das Moças de forma geral, cuidando acima de tudo de um modelo familiar alicerçado na figura do casal, tendo o marido como o "chefe do lar", o "homem ideal" é um marido em potencial e também, sendo um amante do trabalho é capaz de sustentar sua família. É um pai atencioso e responsável, enérgico, mas carinhoso; presente mesmo em sua ausência; aquele que é amado e respeitado e nunca temido. Sendo provedor não falha, cuida da aparência sem exagero. Não é necessariamente bonito, mas deve ser obrigatoriamente forte e viril. É fiel e resiste às tentações mundanas. E antes de tudo, tem ao seu lado aquela que lhe corresponde à altura de sua perfeição.

\section{Referências}

ABREU, Alzira A. de e PAULA, Chriristiane J. (orgs). Dicionário HistóricoBiográfico da Propaganda no Brasil. Rio de Janeiro : FGV/ABP, 2007.

BAUBÉROT, Arnaud. Não se nasce viril, torna-se viril. In: CORBIN, Alain, COURTINE, Jean-Jacques e VIGARELLO, Georges. História da Virilidade: A virilidade em crise? Séculos XX-XXI. Rio de Janeiro : Vozes, 2013. p. 189220.

BRIGGS, Asa e BURKE, Peter. Uma história social da mídia: de Gutemberg à Internet. Rio de Janeiro : Zahar, 2016.

LOBATO, Mayara Luma Maia. A trajetória do feminino na imprensa brasileira:o jornalismo de revista e a mulher do século XX. Ouro Preto: 9.o Encontro Nacional de História da Mídia 2013. Disponível em: http://www.ufrgs.br/alcar/encontros-nacionais-1/9o-encontro-2013/artigos/gthistoria-do-jornalismo/a-trajetoria-do-feminino-na-imprensa-brasileira-ojornalismo-de-revista-e-a-mulher-do-seculo-xx Acesso em: 26/03/2019.

MARTINS, Ana Luiza. Revistas em Revista: imprensa e práticas culturais em tempos de República (1890-1922). São Paulo: Editora da Universidade de São Paulo, 2008.

MARTINS, Ana Luiza e LUCA, Tânia Regina de. História da Imprensa no Brasil. São Paulo : Contexto, 2008.

PINSKI, Carla B. Mulheres dos Anos Dourados. São Paulo : Contexto, 2015. SODRÉ, Nelson.W. História da Imprensa no Brasil. Rio de Janeiro : Civilização Brasileira, 1966. 
VALDÍVIA, Marcia B. A São Paulo glamourosa: encantos e desencantos (1949-1959). São Paulo : PUCSP, 2008. Tese de doutorado. Disponível em: https://tede2.pucsp.br/bitstream/handle/13063/1/Marcia\%20Barros\%20Valdi via.pdf Acesso em: 26/03/2019.

Fontes:

JORNAL DAS MOÇAS, Rio de Janeiro, 05 de janeiro de 1950, n. 1803.

JORNAL DAS MOÇAS, Rio de Janeiro, 06 de abril de 1950, n. 1816.

JORNAL DAS MOÇAS, Rio de Janeiro, 25 de maio de 1950, n. 1823.

JORNAL DAS MOÇAS, Rio de Janerio, 15 de junho de 1950, n. 1826.

JORNAL DAS MOÇAS, Rio de Janeiro, 06 de março de 1951, n. 1864.

JORNAL DAS MOÇAS, Rio de Janeiro, 24 de agosto de 1950, n. 1836.

JORNAL DAS MOÇAS, Rio de Janeiro, 29 de março de 1951, n. 1867.

JORNAL DAS MOÇAS, Rio de Janeiro, 31 de maio de 1951, n. 1876.

JORNAL DAS MOÇAS, Rio de Janeiro, 13 de dezembro de 1951, n. 1904.

JORNAL DAS MOÇAS, Rio de Janeiro, 01 de janeiro de1953, n. 1959.

JORNAL DAS MOÇAS, Rio de Janeiro, 08 de janeiro de 1953, n. 1960.

JORNAL DAS MOÇAS, Rio de Janeiro, 11 de março de 1954, n. 2021.

JORNAL DAS MOÇAS, Rio de Janeiro, 02 de agosto de 1956, n. 2146.

JORNAL DAS MOÇAS, Rio de Janeiro, 31 de janeiro de 1957, n. 2172.

JORNAL DAS MOÇAS, Rio de Janeiro, 25 de julho de 1957, n. 2197.

JORNAL DAS MOÇAS, Rio de Janeiro, 31 de outubro de 1957, n. 2211.

JORNAL DAS MOÇAS, Rio de Janeiro, 30 de novembro de 1957, n. 2215.

JORNAL DAS MOÇAS, Rio de Janeiro, 06 de março de 1958, n. 2229.

JORNAL DAS MOÇAS, Rio de Janeiro, 26 de junho de 1958, n. 2245.

JORNAL DAS MOÇAS, Rio de Janeiro, 24 de julho de 1958, n. 2249.

JORNAL DAS MOÇAS, Rio de Janeiro, 04 e setembro de 1958, n. 2255. 
JORNAL DAS MOÇAS, Rio de Janeiro, 29 de janeiro de 1959, n. 2276.

JORNAL DAS MOÇAS, Rio de Janeiro, 02 de abril de 1959, n. 2285.

JORNAL DAS MOÇAS, Rio de Janeiro, 18 de junho de 1959, n. 2296.

Recebido em março de 2019.

Aprovado em abril de 2019. 